\title{
El acuerdo especial humanitario frente al derecho internacional humanitario
}

\section{The special humanitarian agreement and the international humanitarian law}

\author{
GRETTY PAVLOVICH JIMÉNEZ \\ Abogada, especialista en Derecho Público y en Ciencia Política. \\ Docente Investigadora de la Universidad Libre Seccional Barranquilla. \\ Miembro del Grupo "Poder Público y Ciudadanía de la Universidad Libre \\ gretpav@hotmail.com
}

Recibido: Abril 2 de 2013

Aceptado: Mayo 20 de 2013

\section{RESUMEN}

El tema propuesto para el presente artículo de reflexión plantea como tesis de trabajo el cuestionamiento acerca de si el acuerdo especial humanitario constituye un mecanismo para efectivizar la aplicación del Derecho Internacional Humanitario o si, por el contrario, un mecanismo distorsionador de los alcances del Derecho Internacional Humanitario en el marco de los conflictos armados internos o internacionales. De tal manera que, se trata de abordar el tema desde una perspectiva problema y teniendo como unidad de análisis básica a la sociedad que reconoce en la guerra un fenómeno que crea rupturas dramáticas y dolorosas en el tejido social y frente al cual se debe propender por la prevalencia de la dignidad humana, lo que demanda no solo instrumentos jurídicos, sino también políticos y éticos.

Palabras clave: Acuerdo Especial Humanitario, Derecho Internacional Humanitario, Derechos Humanos

\begin{abstract}
This paperwork raises the question as to whether the special humanitarian agreement provides a mechanism to effect the implementation of international humanitarian law or if, on the contrary, it is a mechanism that distorts the scope of international humanitarian law in the framework of international or internal armed conflict. So that, it comes to addressing the issue from a perspective problem and having society as basic analysis unit that recognizes war phenomenon creates dramatic and painful ruptures in the social fabric and against which efforts must be made by the prevalence of human dignity, which requires not just legal instruments, but also political and ethical ones

Keywords: Special Humanitarian Agreement. International Humanitarian Law, Human Rights
\end{abstract}

\section{Introducción}

El tratamiento de este tema requiere disponer de unos presupuestos teórico conceptuales que sirvan de soporte a la postura de la que se participa en el sentido de que si el acuerdo especial humanitario se diseña por las partes en conflicto teniendo en cuenta solo aquellas disposiciones del Derecho Internacional Humanitario -DIH- que les convienen o que les resultan más favorables en su estrategia de guerra, se corre el riesgo de que al DIH se le reste eficacia y/o se convierta en un objeto de negociación. Es por tal razón que se enfatizará, inicialmente, en el desa- 
rrollo de algunas nociones básicas que conducirán a la sustentación de la postura que se ha anticipado.

\section{Una distinción necesaria entre Derecho Internacional Humanitario-DIH- y Derechos Humanos -DDHH}

Si bien es cierto que el DIH no es lo mismo que DDHH, ello no quiere significar que entre éstos no existan semejanzas o que no participen de propósitos comunes. Es más, entre los mismos se puede hablar de la existencia de complementariedades, que se pueden expresar en que éstos constituyen límites al uso del poder, pero en los DDHH esos límites tienen una sola vía, la del Estado, mientras que en el DIH, esos límites operan en dos vías: la del Estado y la de los actores armados al margen de la ley. Sin embargo, cuando los actores armados al margen de la ley adquieren la condición de sujetos internacionales ${ }^{1}$, se obligan frente a los DDHH con la población bajo su control o dominio. Aunque se advierte que el actor armado al margen de la ley debe en relación con sus miembros o tropa observar los derechos humanos, por lo que, por ejemplo, resulta violatorio de los DDHH la imposición de sanciones que no estén mediadas por el debido proceso dentro del cual el encausado ejerza su derecho a la defensa. De igual manera, entre el DIH y los DDHH se aprecia que ambos comparten el mismo bien jurídico tutelado o protegido, esto es la dignidad humana como el valor intrínseco que tiene toda persona por el solo hecho de serlo, solo que en tratándose del DIH esa dignidad humana se encuentra amenazada o vulnerada en los conflictos armados internacional o no internacionales (internos), mientras que en los DDHH la dignidad humana se protege en momentos tanto de normalidad como de anormalidad y bajo cualquier circunstancia.

De modo que, entre DIH y DDHH opera la tesis de la complementariedad desde ángulos como la favorabilidad al permitirse más instrumentos y más posibilidades de protección y asistencia a la población, a la sociedad, dentro y fuera del conflicto, en estado de normalidad y anormalidad, lo que se puede predicar de la existencia de conflictos en donde se permite un espacio para el ejercicio de DDHH.

\footnotetext{
Los actores armados al margen de la ley al ser reconocidos como beligerantes se convierten en sujetos atípicos del Derecho Internacional Público, aunque esa subjetividad jurídica internacional es temporal, en el sentido de que puede desaparecer porque el grupo beligerante sea vencido o bien porque se transformó en gobierno de ipso, al dominar no solo una parte importante del territorio sino su totalidad, de modo que procede entonces el reconocimiento de gobierno. Sobre el particular se puede consultar los textos de Derecho Internacional Público de Enrique Gaviria Liévano. Temis, Bogotá, 1998, pp., 63-68.
}

Ahora bien, las diferencias entre el DIH y los DDHH se ponen en evidencia en aspectos tales como que el DIH no necesita del reconocimiento de beligerancia a los actores del conflicto al margen de la ley para que tenga cabida, mientras que los DDHH requieren de la condición de sujeto del Derecho Internacional Público para ello; el DIH coloca en un plano de simetría a las partes en conflicto, acaba con el discurso de la irresponsabilidad de los actores armados al margen de la ley frente a las consecuencias de acciones que adelanten en desarrollo de las confrontaciones bélicas, mientras que los DDHH ponen de manifiesto que sus titulares y el Estado no están en el mismo plano, es más la legitimidad de su poder del Estado está en garantizarle a la sociedad los DDHH y una manera de hacerlo es su positivación en las distintas constituciones, al consagrarlos como derechos fundamentales y dotarlos de mecanismos de protección y efectivización ${ }^{2}$. No sin razón se ha expresado que en la actual ola de la globalización, los DDHH son un factor de relativización de la soberanía estatal.

La distinción señalada puede no ser compartida plenamente por los que afirman que el Estado no es el único responsable de la amenaza o violación de los DDHH, en virtud de que existen centros de poder privado o supraestatal, que, en desarrollo de su actividad (terrorismo, narcotráfico, por ejemplo), se tornan, también, en violadores de los DDHH (Arango, 2004. P.27). Esta postura se está abriendo camino y resulta altamente positiva para la reivindicación del sentido de lo humano frente al accionar de estos centros de poder, pero con limitaciones en la concreción de su responsabilidad ya que ello solo deviene por cuenta de la judicialización de sus miembros en el ámbito interno e internacional de los Estados y ligado a la eficacia en la administración de justicia estatal y a la internacionalización de la justicia penal.

En cuanto a lo que significan los DDHH, se aprecia una amplia variedad de definiciones que pretenden dar respuesta a su ontología. Es así como, se consideran atributos de carácter jurídico y moral que le pertenecen a cada individuo, son propios de todos y todas e inherentes a la dignidad humana. Constituyen un ideal ético que responden a un concepto histórico propio del mundo moderno (Peces, 1988. P. 119). De igual manera, los derechos humanos son demandas de libertades, facultades o prestaciones, directamente vinculadas con la dignidad humana o valor intrínseco de todo ser humano, reconocidas como legítimas por la comunidad internacional -por ser

\footnotetext{
La Constitución Política de Colombia de 1991 consagró un catálogo de derechos fundamentales que, inclusive, desbordan el texto constitucional, al reconocerle plenos efectos jurídicos a los tratados y convenios debidamente ratificados y concernientes a los DDHH (artículo 93).
} 
congruentes con principios ético-jurídicos ampliamente compartidos- y por esto mismo consideradas merecedoras de protección jurídica en la esfera interna y en el plano internacional (Grupo Praxis - Universidad del Valle, Cali, 2004). No obstante, existen otros autores que frente a los DDHH más que en indagar en su ontología se detienen en el uso dado a los mismos, en cuyo caso se refieren a relaciones entre las personas para limitar el poder de unas sobre las otras y asegurar los valores más altos de la humanidad y la civilización mediante su sustracción del ámbito de disposición por parte de los diferentes centros de poder. (Arango, 2004.P. 27). Esas relaciones suponen la posibilidad de que cualquiera eleve exigencias a otro para que se comporte o deje de hacerlo de determinada forma (comportamientos negativos y positivos). Con lo cual lo más importante es la práctica de los DDHH en la vida cotidiana de las personas dentro del Estrado para la realización de sus proyectos de vida en el marco de la convivencia social, con los deberes y obligaciones que esto conlleva.

Por su parte, una de las definiciones más claras sobre DIH la ofrece Jean Pictet, cuando afirma que el derecho humanitario es esa considerable porción del derecho internacional público que se inspira en el sentimiento de humanidad y que se centra en la protección de la persona en caso de guerra. (Pictet, 1986.P. 9). Así mismo, el Comité Internacional de la Cruz Roja sostiene que DIH es:

...el cuerpo de normas internacionales, de origen convencional o consuetudinario, específicamente destinado a ser aplicado en los conflictos armado, internacionales o no internacionales, y que limita, por razones humanitarias, el derecho de las partes en conflicto a elegir libremente los métodos y los medios utilizados en la guerra, o que protege a las personas y los bienes afectados, o que pueden estar afectados, por el conflicto (Swinarski, 1984.p.15).

En otros términos, el profesor Alejandro Valencia Villa manifiesta que más allá del concepto mismo de DIH, su fundamento central es reconocer el hecho de la existencia de la guerra, y en lugar de tratar de evitarla, labor que parece imposible, procura disminuir sus efectos en las personas que no participan o han dejado de participar en las hostilidades. Sostiene, además, que la principal razón que inspira la normatividad humanitaria, es un profundo sentimiento hacia la dignidad humana, pues de otra manera, la barbarie y la destrucción serían los desenlaces inexorables de los conflictos armados. (Valencia, 2007. P.16).

Las anteriores definiciones de DIH ponen de manifiesto los siguientes rasgos característicos de esta disciplina jurídica:

\section{Caracterización del DIH para refutar aspiraciones que exceden su núcleo conceptual}

Al DIH se le suelen atribuir cualidades que no le son propias, no importa cuan altruistas puedan o pretendan ser éstas, porque no se trata de insuflar a esta disciplina jurídica sino de guardar su rigor conceptual y, en este mismo sentido, de dimensionar su verdadero alcance no solo en los conflictos armados sino en la sociedad misma. Así las cosas, el DIH se caracteriza por su naturaleza humanitaria, su carácter regulador, ser un código ético de conducta para los actores del conflicto y un sistema normativo.

De conformidad con lo anterior, el DIH no es un código penal ni disciplinario y no es un instrumento para la consecución de la paz, pero, eso sí, su aplicación puede facilitar procesos de paz, reconciliación y reconstrucción nacional. El DIH no opera a nivel de las causas generadoras de los conflictos armados, sino a nivel de los efectos que se derivan de éstos.

Véase muy sucintamente cual es la significación de cada una de las características señaladas:

- La característica de ser humanitario. Se expresa en la asistencia y protección que ofrece a quienes resulten siendo las víctimas del conflicto o sus potenciales afectados. La asistencia se refiere a la forma de cubrir las necesidades inmediatas para la supervivencia y la protección, a las acciones que emprende para salvar de un peligro inminente. La garantía de su prestación es imparcial, no sujeta a discriminación, a excepción de la condición de vulnerabilidad y del estado de urgencia. Precisamente, la imparcialidad tiene que estar incita en lo humanitario porque de lo contrario deja de serlo;

- La característica de ser regulador. El DIH regula el procedimiento o la forma de hacer el combate, es decir, los métodos y medios empleados por los actores del conflicto, de tal manera que se de el mayor número de rendiciones y el menor número de bajas. Esa regulación reivindica la noción de que al enemigo no hay que destruirlo sino neutralizarlo, restándole capacidad de maniobra en medio del conflicto. A la guerra hay que restarle víctimas potenciales y reales.

- La característica de ser un código ético que se dirige a la conducta de los actores del conflicto. En este sentido, el DIH tiene la confianza de que los portadores de las armas las utilicen bien, de que libren una guerra limpia. Igualmente, nos remite al deber de los Estados de desarrollar normatividad penal y humanitaria y de los actores armados al margen de la ley de incluir el DIH en sus estatutos o reglamentos internos; $y$ 
La característica de ser un sistema normativo. El DIH comprende un conjunto de normas contenidas en los cuatro Convenios de Ginebra de 1949, el artículo 3 común a los mismos y sus dos protocolos adicionales de 1977. Es decir, existe todo un cuerpo normativo para evitar o disminuir los efectos derivados de los conflictos armados, sean éstos internacionales o no internacionales (internos), sin que la aplicación del mismo conceda estatus jurídico ni político especial a los actores del conflicto. En general la doctrina admite que los actores armados al margen de la ley se encuentran obligados por el principio de jurisdicción interna a respetar el Artículo 3 Común y el Protocolo II Adicional a los Convenios de Ginebra. Por consiguiente, los insurgentes están vinculados con la legislación interna y, dentro de ésta, con los tratados o convenios internacionales legalmente incorporados a la legislación nacional, también por el carácter consuetudinario de las citadas normas. Sin embargo, debido a la ausencia de un sistema que obligue el acatamiento del DIH lo que resulta más importante es obtener la real voluntad de los actores armados al margen de la ley de respetar este ordenamiento jurídico, por encima de la discusión de si están o no cobijados por sus normas.

A propósito de este último aspecto, ante la ausencia de un mecanismo represivo que abogue por el respeto obligatorio del Derecho Internacional Humanitario, la discusión sobre la oponibilidad de sus normas frente a los grupos armados ilegales puede resultar superflua para algunos expertos. En la medida en que la actividad de los actores armados al margen de la ley se encuentra legalmente prohibida por las legislaciones internas de sus respectivos Estados, el DIH sólo les representa un nivel mayor de ilegalidad, de connotación superior a la nacional, que no les significa una mayor ventaja sobre su oponente de la cual extraerá algún tipo de beneficio. De ahí que se considera de suma importancia encontrar la manera para que el reconocimiento del DIH les resulte atractivo a los actores armados al margen de la ley, como vendría a ser la institución del reconocimiento de beligerancia.

\section{El acuerdo especial humanitario}

Muchos temas humanitarios están atravesados por factores políticos y esta es tal vez la principal motivación para esclarecer la noción de acuerdo especial humanitario, al que pueden arribar los actores del conflicto por voluntad política y/o humanitaria.

Los acuerdos especiales son acuerdos que las Partes en conflicto pueden concertar entre ellas para mejorar o completar las normas estipuladas en: G I, art.6; G II, art. 6; G III, art. 6;G IV, art. 7; GP I; GP II; H CP (Verri, 1998. P. $6,17)$. Esta definición remite a las normas contenidas en los artículos que en los Convenios de Ginebra se titulan 'acuerdos especiales', según los cuales los Estados pueden concertar este tipo de acuerdos sobre cualquier cuestión que les parezca pertinente definir particularmente, aclarando que estos no perjudicarán la situación de las personas protegidas. Las siguientes referencias normativas son el Protocolo I y II en su integridad, y la Convención para la Protección de los Bienes Culturales de la Haya.

El CICR -Comité Internacional de la Cruz Roja- ha ido ampliando la definición precedente de acuerdo especial humanitario con el objeto de promoverlos como uno de los mecanismos jurídicos viables actualmente para mejorar la aplicación del DIH en conflictos armados internos, a partir de la siguiente enunciación:

...Según lo dispuesto en el artículo 3 común, los acuerdos especiales autorizan a las partes en conflictos armados no internacionales (entre un Estado y uno o más grupos armados o entre grupos armados) a comprometerse explícitamente a respetar el derecho humanitario.

Un acuerdo especial puede crear nuevas obligaciones jurídicas, si va más allá de las disposiciones del DIH ya aplicables en las circunstancias específicas (un acuerdo "constitutivo"), o bien retomar simplemente el derecho que ya vincula a las partes (un acuerdo "declarativo"). Asimismo, puede limitarse únicamente a ciertas normas específicas que, en el marco de un conflicto en curso, pueden adquirir una pertinencia particular. En este caso, el acuerdo debe establecer claramente que, pese a su alcance limitado, sus disposiciones se aplicarán sin perjuicio de lo dispuesto en las otras normas aplicables que no se mencionan en él. (Mack, 2008. P. 16, 39).

Con esta nueva definición se amplían los alcances de los acuerdos humanitarios, ya que no los limita a que sean aplicados frente a unos instrumentos jurídicos concretos, sino que incluso abre la posibilidad de realizar acuerdos que superen las disposiciones de la normatividad humanitaria, lo que definen como acuerdos constitutivos que, en todo caso, no desmejoren el régimen de protección conferido. Por otra parte, en el texto de Comentario del artículo 3 común, se aclara que si bien las partes en conflicto no están obligadas a acatar más que el propio artículo 3, si están obligadas a hacer todo lo posible para ampliar la aplicación del DIH en los conflictos armados internos. En este sentido, un acuerdo especial humanitario para efectos de su legalidad no puede ir en detrimento del DIH o restarle su eficacia en la regulación del conflicto armado no internacional, lo que reafirma su carácter jurídico aunque sea producto de una negociación política entre actores armados en conflicto. 
Para reafirmar lo anterior, valga traer a colación otra definición de acuerdo especial humanitario como un acuerdo que podría ir más allá del mínimo que ya está contenido en el Derecho Internacional Humanitario. (Comninos, 2002).

En su momento, Alfonso López Michelsen se refirió al acuerdo especial humanitario como "un mecanismo para proceder, en aras del Derecho Internacional Humanitario, a aliviar una situación penosa, sin reconocer vencedores ni vencidos, y sin negociación de ninguna clase de carácter político" ${ }^{\prime \prime}$.

El acuerdo especial humanitario es un mecanismo que, en estricto rigor y conforme lo prescriben los Convenios de Ginebra, constituye una institución especial que no es imperativa sino opcional de los actores en conflicto, asistidos por el principio de igualdad que inspira el acuerdo especial humanitario. Concretamente, el artículo 3 común a los Convenios de Ginebra de 1949 permite a las partes en un conflicto armado de carácter no internacional, convenir la vigencia de otras normas del DIH con el propósito de ampliar los marcos de protección. ${ }^{4}$ De ahí, que un acuerdo especial humanitario no se compadece con la idea de un acuerdo político con características o fines humanitarios. Cuando se invoca el acuerdo especial humanitario se impone por igual el sometimiento al DIH en virtud de su carácter imperativo. Por consiguiente, la categoría de acuerdos especiales dentro del DIH es mucho más amplia, y podría incluir tantos temas como quisiesen las partes contendientes, como por ejemplo, extender la aplicación de los Convenios de Ginebra a una situación de un conflicto interno. Uno de los propósitos que tienen estos acuerdos especiales es integrar los instrumentos del DIH a la realidad de los conflictos, es decir llevarlos a la práctica. No se trata de repetir en los acuerdos humanitarios los contenidos del Derecho Internacional Humanitario, sino convenir la forma de su aplicación efectiva. Lo que representa el esfuerzo y compromiso de las partes de aterrizar estas normas al conflicto existente entre ellas.

No se puede lograr ni siquiera concebir acuerdo especial humanitario que menoscabe las exigencias mínimas del DIH porque sería supeditar el carácter imperativo de sus normas a la negociación que las partes del conflicto realicen de éstas, al ponerlas en contraste con sus intereses, resultados militares, etc. Estos son algunos de los riesgos

\footnotetext{
Definición contenida en su columna habitual del periódico "El Tiempo" en su edición del 11 de enero de 2004.

4 El artículo 3 común, en el aparte "como mínimo" Las disposiciones aplicables representen (sic) un mínimo obligatorio. Al mismo tiempo es una invitación para superar este mínimo". Separata editada por la Delegación del Comité Internacional de la Cruz Roja (CICR) en Colombia.
}

que corre el DIH cuando se plantea la adopción del acuerdo especial humanitario antes que apelar a otros recursos, como una negociación directa o una victoria militar.

Estos riesgos, sin embargo, no pueden conducir a negar las ventajas que el acuerdo especial humanitario, rigurosamente adoptado, puede reportar en la regulación del conflicto por parte del DIH, como es su carácter supranacional, al incorporarse al bloque de constitucionalidad, lo que eximiría al gobierno (en el caso del Gobierno Colombiano, por ejemplo) de apelar a las facultades extraordinarias de orden doméstico. De esta manera, lo que en el contexto colombiano se entiende como acuerdo o intercambio humanitario, podría ser uno de los muchos tipos de acuerdos especiales que permite y promueve el DIH en contextos de conflicto armado no internacional.

En desarrollo de esta línea argumentativa, se retoma la tesis planteada al inicio de este artículo al señalar el cuestionamiento acerca de si el acuerdo especial humanitario constituye un mecanismo para efectivizar la aplicación del Derecho Internacional Humanitario o si por el contrario, un mecanismo distorsionador de los alcances del Derecho Internacional Humanitario en el marco de los conflictos armados no internacionales. El acuerdo especial humanitario es o debe ser un plus o valor agregado en la aplicación y efectividad del DIH si se le adopta con rigor, o lo que es lo mismo, sin limitar o desconocer el núcleo "duro" del mismo, es decir, el sentido de lo humanitario en la guerra representado en la dignidad humana de las personas ajenas al conflicto y de quienes han dejado de ser parte del mismo.

La existencia de un conflicto armado interno en Colombia, con una vigencia de más de cincuenta años, bien habilita a las partes para celebrar un acuerdo especial humanitario, si se tiene en cuenta la sujeción debida por parte de las mismas al DIH. Esta sujeción deviene no solo de que el Estado colombiano ha incorporado válidamente tratados o convenios internacionales sobre DIH a su ordenamiento jurídico interno sino que dentro del DIH existen normas de origen consuetudinario, así como normas de ius cogens que tienen, igualmente, fuerza vinculante. Aunque con imprecisiones conceptuales entre normas consuetudinarias y normas de ius cogens, la misma Corte Constitucional Colombiana ha reafirmado el carácter obligatorio del DIH, valga solo remitir a la SC- 225 de 1995.

La definición objetiva de la existencia del conflicto armado, es parte esencial para cumplir las finalidades del DIH de garantizar un sistema de protección. Caso contrario, se estaría en presencia de una tesis severamente peligrosa de conceder poder de definición de existencia del conflicto a cualquier tipo de autoridad y quitarle la posibilidad 
de aplicación automática a la normatividad humanitaria. Razón por la cual resulta pertinente traer a colación la definición de conflicto armado no internacional en los términos dispuestos en artículo 1 del Protocolo II de 1977:

"1. El presente Protocolo, que desarrolla y completa el artículo 3 común a los Convenios de Ginebra del 12 de agosto de 1949, sin modificar sus actuales condiciones de aplicación, se aplicará a todos los conflictos armados que no estén cubiertos por el artículo 1 del Protocolo adicional a los Convenios de Ginebra del 12 de agosto de 1949 relativo a la protección de las víctimas de los conflictos armados internacionales (Protocolo I) y que se desarrollen en el territorio de una Alta Parte contratante entre sus fuerzas armadas y fuerzas armadas disidentes o grupos armados organizados que, bajo la dirección de un mando responsable, ejerzan sobre una parte de dicho territorio un control tal que les permita realizar operaciones militares sostenidas y concertadas y aplicar el presente Protocolo".

De conformidad con esta definición los elementos principales de un conflicto armado de carácter no internacional, son las siguientes:

1. Que se desarrolle en el territorio de una alta parte contratante. El conflicto se desarrolla dentro de los límites de un Estado. No obstante, el hecho de que las fuerzas armadas o los grupos organizados partan de un territorio extranjero o utilicen éste como centro de operaciones, o reciban ayuda económica de un tercer Estado, no altera la calificación ni la naturaleza del conflicto armado interno.

2. Que se enfrente entre sus fuerzas armadas y fuerzas armadas disidentes o grupos armados organizados. En relación con este elemento es preciso señalar que por su redacción parece excluirse del ámbito de aplicación del Protocolo II, los conflictos armados internos donde no haya intervención de las fuerzas armadas estatales. De otra parte, también genera controversia el término "fuerzas armadas", pues no existe claridad si también cobija a organismos de seguridad como la policía, que en algunos países tiene un carácter civil, como es en el caso Colombiano, pero que sin embargo en la práctica desarrolla actividades militares dentro de las hostilidades. Sobre este particular no hubo acuerdo entre las delegaciones de los Estados para definir el alcance de esta noción.

3. Que estas fuerzas armadas o grupos organizados estén bajo la dirección de un mando responsable. Esta autoridad se ejerce no sólo en la dirección de las hostilidades, sino también en la imposición de disciplina a los subordinados, de esta manera también asume la responsabilidad por los actos de estos últimos.
4. Que se ejerza un control sobre una parte del territorio. Uno de los puntos más debatidos frente a este elemento, es la definición de cual debería ser la porción de territorio sobre la cual se ejerza el control, ya que la normatividad no ofrece una estipulación exacta de esta cantidad. No obstante, esta porción de territorio estaría definida por la funcionalidad que tiene, en este caso, la porción de territorio debe ser la necesaria para ejercer operaciones militares sostenidas, y aplicar el Protocolo, principalmente en relación con la ubicación de las personas privadas de la libertad y el cuidado de los heridos y enfermos.

5. Que se realicen operaciones militares sostenidas y concertadas. Este tipo de operaciones son las que aseguran el control del territorio. La calificación de sostenidas y concertadas, más que tratar de definir una duración e intensidad de las hostilidades, lo que pretende es ofrecer un elemento diferenciador de situaciones de violencia aisladas y esporádicas, que no alcanzarían a considerarse como conflicto armado. En este sentido, diferenciar el conflicto de una mera perturbación del orden público dentro del Estado.

6. Que el control ejercido sobre el territorio permita aplicar el Protocolo II. Se hace alusión a obligaciones de hacer, por parte de los grupos armados, y que requerirían algún espacio concreto. En el caso de conflictos armados internos, estas obligaciones estarían relacionadas con el cuidado de los heridos, o el trato debido a los prisioneros, para cumplir con lo establecido en los artículos 4 y 5 del Protocolo, que regulan las garantías fundamentales y el régimen de personas privadas de la libertad.

En la configuración del conflicto armado no internacional para la delimitación del campo de aplicación del Protocolo II es importante aclarar que las situaciones de conflicto que queden por fuera del mismo, o que no cumplan con alguno de los elementos consagrados, de ninguna manera quedan desprovistos de protección, ya que siguen siendo reguladas por el derecho humanitario, pero por vía del artículo 3 común. En efecto, en la práctica el CICR puede invocar siempre la aplicación de ese mínimo humanitario en los conflictos no cubiertos por el Protocolo II.

Esta definición de conflicto armado interno registra una significativa evolución, sobre todo a partir de la jurisprudencia internacional y siempre bajo la intencionalidad de evitar la subjetividad en la consideración de los elementos que se han tener en cuenta para la existencia del conflicto armado no internacional. Dentro de la jurisprudencia internacional el caso Tadic ${ }^{5}$, del Tribunal Penal

\footnotetext{
El Tribunal Penal Internacional para la antigua Yugoslavia encontró a Tadic culpable de 12 de los 34 cargos formulados, a los que pre-
} 
Internacional para la antigua Yugoslavia, sentó un precedente fundamental en la determinación de cuando se está frente a un conflicto armado interno, al plantear estos dos aspectos: la organización de las partes en conflicto y la intensidad de las hostilidades. Verificados estos dos presupuestos en un caso concreto, se constituiría una situación de conflicto armado, susceptible de ser regulado por el DIH. Esta última posición dentro del derecho internacional parece estar en mayor concordancia con el espíritu de protección de la normativa humanitaria.

En Colombia la existencia del conflicto armado interno es corroborada por la Ley 1448 de 2011, Ley de víctimas y restitución de tierras, cuando en la primera parte de su artículo 3, dispone:

"Se consideran víctimas, para los efectos de esta ley, aquellas personas que individual o colectivamente hayan sufrido un daño por hechos ocurridos a partir del 1o de enero de 1985, como consecuencia de infracciones al Derecho Internacional Humanitario o de violaciones graves y manifiestas a las normas internacionales de Derechos Humanos, ocurridas con ocasión del conflicto armado interno".

A partir de anteriores precisiones, en el marco de la significación y alcances del acuerdo especial humanitario dentro del conflicto armado no internacional, cabe decantar en el terreno de lo fáctico los planteamientos formulados para, en primer lugar, distinguir cuando se estaría en presencia de un acuerdo especial humanitario y, en segundo lugar, precisar sus implicaciones dentro del DIH.

En lo que respecta al primer punto, considérese que frente a un intercambio de secuestrados no se estaría en presencia de un acuerdo especial humanitario, sino de un acuerdo político con características humanitarias. La toma de rehenes es claramente violatoria del DIH, luego, entonces, el o los actores del conflicto armado que tengan en su poder a rehenes tienen la obligación de liberarlos, sin

\footnotetext{
viamente se había declarado inocente de todos ellos. Dusko Tadic fue condenado a 20 años de prisión $(14 / 07 / 1997)$, con prohibición de ser liberado antes del 14 de julio de 2007, tras no mostrar señal alguna de arrepentimiento por sus actos y por "no haber cooperado de manera relevante con el Fiscal del Tribunal". Tadic fue encontrado culpable por violaciones a las leyes o costumbres de guerra (5 cargos) y por cometer crímenes contra la humanidad (6 Cargos), siendo éste responsable por los asesinatos, maltratos y posterior desplazamiento forzoso de la población, ya como autor principal o accesorio, en los ataques sobre la población de Kozarac en Opstina Prijedor, en el noroccidente de Bosnia. Dusko Tadic, oficial de baja graduación, "no fue condenado por cometer directamente un acto de agresión sexual sino por su participación en una amplia campaña de terror, generalizada y sistemática, que consistió en golpizas, torturas, agresiones sexuales y otros abusos físicos y psicológicos contra la población no serbia de la región de Prijedor.
}

contraprestación alguna. Pero, es posible que el Estado, en procura de la devolución de las personas víctimas de esta infracción al DIH, propicie un acuerdo especial humanitario, sin que medie negociación de carácter político y en sujeción de las partes del conflicto a las normas del $\mathrm{DIH}^{6}$. Por consiguiente, el acuerdo especial humanitario no se construye sobre la violación o el desconocimiento del DIH sino sobre su observancia y en un claro propósito de concretar la aplicación de sus normas en la realidad del conflicto para atender sus propósitos de protección. No se trata, entonces, de un acuerdo en el que las partes negocian mutuas concesiones para que el comportamiento de las mismas se adecue a condiciones políticas, sobre las que ninguno de los actores armados tenga la percepción de que ha perdido en la dinámica de la guerra. Implica, por el contrario, un compromiso con lo humanitario en la conducción y desenvolvimiento de las hostilidades y sus efectos tanto para quienes están inmersos en el conflicto como para quienes están por fuera del mismo.

Por otro lado, el acuerdo especial humanitario podría concluir con un cese de hostilidades, acuerdos de paz y compromisos, por ejemplo. De tal manera que, se establecería un nuevo marco de acción entre los actores del conflicto armado que repercuten en la regulación que de éste hace el DIH.

\section{A manera de conclusiones}

Hablar de DDHH y de DIH es hacer referencia a dos escenarios del mundo de lo jurídico que encuentran en la dignidad de la persona humana un bien jurídico de protección, de tutela, en todo momento y lugar, para el caso de los primeros, y en los conflictos armados internacionales y no internacionales (internos), para el caso del segundo, frente a los cuales existen compromisos del Estado, de la Sociedad y de la Comunidad Internacional e, inclusive, de los actores armados al margen de la ley. No obstante, las precisiones conceptuales entre uno y otro derecho ayudan a comprender sus alcances y posibilidades de realización o efectivización.

El DIH ha dado lugar a un sin número de aspiraciones que convergen, en gran mayoría, en concebirlo como un instrumento de paz, cuando en realidad es uno de los que debería servir para minimizar las consecuencias de la guerra que es su ámbito de aplicación.

En el acuerdo especial humanitario así como se puede ser un mecanismo que posibilita incrementar la efectividad

\footnotetext{
Opinión del ex asesor político de la ONU en el Salvador, don Ernesto Borda Medina, dada al periódico "El Tiempo" el 3 de marzo de 2002.
} 
del DIH, puede convertirse en un mecanismo distorsionador de los alcances de este ordenamiento normativo cuando se pretende adoptar menoscabando las exigencias mínimas de este derecho.

Finalmente, si en Colombia se abre paso a una propuesta de acuerdo especial humanitario que no precise de una normativa adicional de carácter interno, se podría acudir directamente a la aplicación del Derecho Inter- nacional, teniendo como fundamento lo consagrado en el artículo 3 común a los Convenios de Ginebra, para aumentar la protección conferida por el DIH en una situación de conflicto armado interno. No obstante es importante recordar que a nivel interno, esta normatividad es vinculante como parte del bloque de constitucionalidad. Se advierte que ese acuerdo especial humanitario podría incluir tantos temas como lo dispusieran las partes contendientes.

\section{Referencias}

Arango, R. (2004). Derechos, Constitucionalismo y Democracia. Universidad Externado de Colombia. Bogotá.

Comité Internacional de la Cruz Roja. Normas fundamentales de los convenios de Ginebra y de sus protocolos adicionales. Ginebra.

Comninos, G. (2002). Entrevista. Bogotá. Periódico “El Tiempo" 3 de marzo de 2002.

Convenios de Ginebra. Artículo 3 común a los convenios.

Gaviria Liévano, E (1998). Derecho Internacional Público. Temis. Bogotá.

López Michelsen, A (2004). Alcance del Acuerdo Humanitario. Periódico El Tiempo. Bogotá. 16/08 / 2004.

López Sacconi, F. (1998). Módulo de Derecho Internacional Humanitario. Especialización en Ciencia Política. Convenio Universidad de Bucaramanga- Universidad del Atlántico. 1998.

Mack, M. (2008). Mejorar el respeto del Derecho Internacional Humanitario en los conflictos armados no internacionales. Comité Internacional de la Cruz Roja - CICR. Ginebra.

Ortiz Alhf, L. (1997) Derecho Internacional Público. Harla. México.

Peces- Barba, G, (1988). Escritos sobre Derechos Fundamentales. Eudema. Madrid.

Pictet, J (1986). Desarrollo y principios del Derecho Internacional Humanitario. Instituto Henry Dunnant. Ginebra.

República de Colombia. Corte Constitucional Colombiana Sentencia C- 225 de 1995.

República de Colombia. Constitución Política de Colombia de 1991. Editorial Leyer.

Swinarsky, Chr (1984) Introducción al Derecho Internacional Humanitario. Comité Internacional de la Cruz Roja. Instituto interamericano de Derechos Humanos. San José, Costa Rica - Ginebra, Suiza. 1984.

Valencia Villa, A (1994). Derecho humanitario para Colombia. Defensoría del Pueblo. Bogotá.

Verri, Pietro, (1998). Diccionario de Derecho Internacional de los Conflictos Armados. Comité Internacional de la Cruz Roja - CICR. Ginebra. 